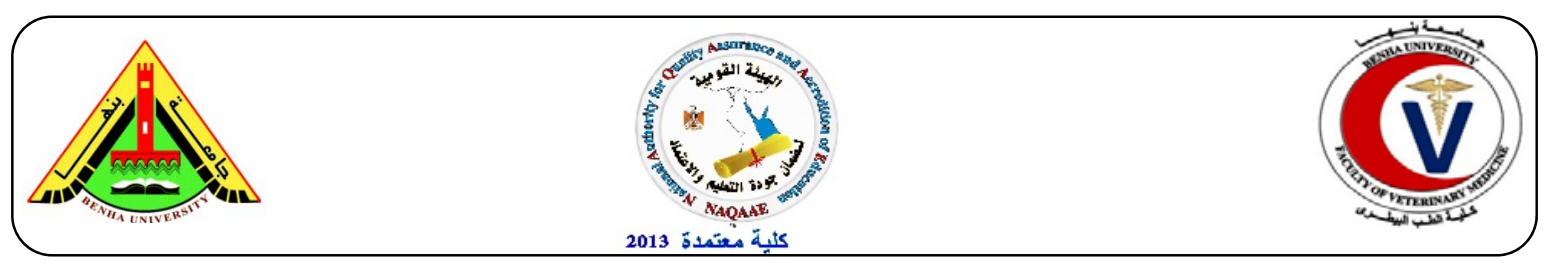

\title{
Chemopreventive effect of omega- 3 fatty acids in N-nitrosodiethylamine Induced hepatocellular carcinoma in rats
}

\author{
Samy Ali Hussein ${ }^{1 *}$; Tahya E.A. Esmeal'; Aziza Amin ${ }^{3}$ and Eman, A.M. Sarhan ${ }^{1}$ \\ ${ }^{1}$ Biochemistry Department, Faculty of Vet. Med., Benha University, Egypt. ${ }^{2}$ Nutrition and clinical \\ nutrition department, Faculty of Vet. Med., Benha University, Egypt. ${ }^{3}$ Pathology Department, Faculty \\ of Vet. Med., Benha University, Egypt. *Corresponding author: E-mail: Samyaziza@yahoo.com
}

\begin{abstract}
A B S T R A C T
Liver cancer, predominantly hepatocellular carcinoma (HCC), represents a complex and fatal malignancy driven primarily by oxidative stress and inflammation. The chemopreventive effect of omega-3 on inflammatory markers and oxidative damage, caspase-3, antioxidant status and histopathological alterations in hepatic tissue in N-nitrosodiethylamine (DEN)-induced HCC in male rats was investigated. To induce HCC, rats were given DEN (200 mg/kg b.wt.,i.p) three times at a 15 day interval. 75 rats were divided into five equal groups. Control group, DEN group, DEN $+\omega 3$ protected group received omega-3 $(270 \mathrm{mg} / \mathrm{kg}$ b. wt/day) orally 4 weeks before DEN injection and continued to 13 weeks, DEN $+\omega 3$ treated group firstly injected with DEN and orally treated with omega3 from the $8^{\text {th }}$ week till the end of the experiment $\left(13^{\text {th }}\right.$ week) and normal $-\omega 3$ group received omega-3. Blood samples and liver tissues were collected at $13^{\text {th }}$ week. DEN-induced HCC significantly decreased SOD and CAT activities in liver tissue. However, a marked increase in liver tissue L-MDA, DNA fragmentation, caspase- 3 and Nf-kB P65 and in serum AFP, IL- 6 and TNF- $\alpha$ levels were observed in DEN injected rats. Initiation of HCC was demonstrated by histopathological examination of hepatic tissue in DEN injected group. Histopathological examination confirmed the pathological improvement in the liver of rats in omega -3 protected and treated groups. In conclusion, omega-3 demonstrates antiinflammatory property by suppression of TNF-alpha and IL- 6 due to inhibition of NF-kB p65 and exerts its chemopreventive effect on liver carcinogenesis. These data suggest that omega-3 exhibited significant protection against DEN-induced HCC, which might be related with the enhancement of the antioxidant activity and the induction of apoptosis.
\end{abstract}

Key Words: Hepatocellular carcinoma, Omega-3, inflammatory mediators, oxidative damage, Histopathology.

(http://www.bvmi.bu.edu.eg)

(BVMJ-30(1): 150-160, 2016)

\section{INTRODUCTION}

$\mathrm{H}$ epatocellular carcinoma ( $\mathrm{HCC})$ is the most common primary malignancy of the liver. HCC is the third leading cause of cancer mortality worldwide, with approximately 700,000 new cases diagnosed every year. HCC typically develops in patients with chronic liver disease. Among these, viral hepatitis, nonalcoholic fatty liver disease, and alcoholic liver disease are the leading causes of HCC. Chronic liver injury, triggering permanent hepatocellular damage, hepatocyte regeneration, and inflammation, is thought to be the unifying principle that promotes carcinogenesis in these pathophysiologically distinct diseases (Saini et al., 2006; Forner et al., 2012 and $\mathrm{Mu}$ et al., 2015). $N$-Nitrosodiethylamine (DEN) is a strong hepatocarcinogenic dialkylnitrosoamine present in tobacco smoke, water, cheddar cheese, curd and fried meals and in a number of alcoholic 
beverages. Such compound is known to cause perturbations in the nuclear enzymes involved in DNA repair/replication and producing reproducible $\mathrm{HCC}$ after repeated administration in experimental animals (Balamurugan and Karthikeyan, 2012).

Since the mid-1980s, omega-3 fatty acids (O3FAs) have a renewed interest that led to consideration of their role in the cause and management of diverse diseases such as psychiatric (Freeman, 2000; Su et al., 2003 and Arvindakshan et al., 2003), cardiovascular disorders (Mata Lopez and Ortega, 2003 and Leaf et al., 2003), inflammatory bowel disease (Simopoulos, 2002), and cystic fibrosis (De Vizia et al., 2003). The O3FAs, present in fish oil, interfere with the arachidonic acid pathway of inflammation and can also modulate the response of macrophages to endotoxin by inhibition of TNF- $\alpha$ production in vitro. Dietary O3FAs can decrease IL-6 and other proinflammatory cytokine levels as well, both in vitro and in vivo (Alwayn et al., 2005). Furthermore, O3FAs have been shown to accelerate the clearance of chylomicron triglycerides in humans, thus effectively reducing triacylglycerol concentrations in serum in vivo (Park and Harris, 2003). Moreover, it has been demonstrated that the administration of fish oil reduces parenteral nutrition-induced cholestasis in newborn piglets and rats and that dietary omega-3 and omega- 6 polyunsaturated fatty acids can regulate hepatic lipogenesis by reducing sterol regulatory element-binding protein- 1 in the liver (Alwayn et al., 2005). Finally, a clinical study that compared 19 patients who had nonalcoholic fatty liver disease with 11 normal control subjects revealed that patients with nonalcoholic fatty liver disease had a higher ratio of long-chain polyunsaturated fatty acids omega6/omega-3 in their livers than did control subjects (Araya et al., 2004). Thus, the present study aimed to evaluate the beneficial effects and chemopreventive potential of Omega-3 on experimentally induced liver cancer by $\mathrm{N}$ -
Nitrosodiethylamine, DEN (Diethylnitrosamine), through evaluation of some serum liver biomarkers, evaluation of some liver tissues antioxidant parameters, histopathological examination of liver samples and evaluation of some DNA fragments.

\section{MATERIAL AND METHODS}

\subsection{Experimental animals:}

Seventy five white male albino rats of 4-5 weeks old and weighting 100-150 gm were used in the experimental investigation of this study. The rats were obtained from the Laboratory Animals Research Center, Faculty of Veterinary Medicine, Benha University. Rats were housed in separated wire mesh cages and kept at constant environmental and nutritional conditions throughout the period of experiment. The animals were fed on constant ration and fresh, clean drinking water was supplied adlibitum. The animals were left 7 days for acclimatization before the beginning of the experiment.

\subsection{Omega-3.}

Physical properties: Omega-3 fatty acids manufactured by South Egypt Drug Industries Co. (SEDICO), 6 October City Egypt. Omega-3 fatty acids present in a soft gelatin capsulated form with $1000 \mathrm{mg}$ concentration in each capsule. Each capsule contains EPA 18\%, DHA 12\%, $1000 \mathrm{mg}$ \&wheat germ oil (Tocopherol: NN.T. $0.22 \%) 100 \mathrm{mg}$. Preparation and dosage of Omega-3: Omega-3 fatty acids were dissolved in propylene glycol and were administered orally in a daily dose of 270 $\mathrm{mg} / \mathrm{kg}$ body weight (Paget and Barnes, 1964).

\subsection{Induction of hepatic carcinogenesis:}

Physical properties: N-nitrosodiethylamine presents in a clear yellow liquid form with the molecular formula $\mathrm{C}_{4} \mathrm{H}_{10} \mathrm{~N}_{2} \mathrm{O}$ and molecular weight $102.14 \mathrm{~g} / \mathrm{mol}$. It was kept in room temperature. DEN was purchased from Sigma Aldrich Company for Trading Chemicals, Medicines and Medical 
Appliances, Egypt. Preparation and dosage of DEN: DEN was freshly prepared in normal saline (Singh et al., 2009), and injected to rats at a dose of $200 \mathrm{mg} / \mathrm{kg} \mathrm{b.wt}$ (i.p) three times at an interval of 15 days (Khan et al., 2011).

\subsection{Experimental design:}

Rats were randomly divided into five main equal groups, 15 rats each, placed in individual cages and classified as follow: Group 1: Control Normal group: received no drugs, served as control non-treated for all experimental groups. Group (2): DEN (Positive control) group: Rats considered as the carcinogen control injected with DEN at a dose of ( $200 \mathrm{mg} / \mathrm{kg}$ body weight i.p) three times at an interval of 15 days at experimental weeks 2, 4 and 6. Group (3): $\mathrm{DEN}+\omega 3$ protected (co-treated) group: Rats were pretreated with Omega-3 at a dose of $(270 \mathrm{mg} / \mathrm{kg} \mathrm{b}$. wt, daily) (beginning from the $2^{\text {nd }}$ week) till the end of experiment. Rats injected with DEN $(200 \mathrm{mg} / \mathrm{Kg}$ body weight) at experimental weeks 6,8,10. Group (4): DEN $+\omega 3$ treated (Post-treated) group: Rats injected with DEN (200mg/Kg b.wt, i.p) at experimental weeks 2,4 and 6 similar to group 2 and subsequently treated with omega-3 at a dose of $\left(270 \mathrm{mg} / \mathrm{kg} \mathrm{b} . \mathrm{wt}\right.$, orally) from the $8^{\text {th }}$ week (beginning 2 week after the last dose of DEN)till the end of the experiment. Group (5): $\omega 3$ normal treated group: Rats were administrated Omega-3(270mg $/ \mathrm{kg}$ b.wt, daily, orally) starting from the $2^{\text {nd }}$ week till the end of experiment.

\subsection{Sampling:}

Blood samples and tissue specimens (liver tissues) were collected at the end of experiment on $13^{\text {th }}$ week for all groups (control and experimental groups).

\subsubsection{Blood samples:}

Blood samples for serum separation were collected by ocular vein puncture at the end of each experimental period in dry, clean, and screw capped tubes and serum were separated by centrifugation at 2500 r.p.m for 15 minutes. The clean, clear serum was separated by automatic pipette and received in dry sterile samples tube and kept in a deep freeze at $-20^{\circ} \mathrm{C}$ until used for subsequent biochemical analysis .All sera were analyzed for Alpha- Fetoprotein, Interleukin- 6 and tumor necrosis factor alpha determination.

\subsubsection{Liver tissue samples:}

For biochemical analysis: At the end of the experiment, rats of each group were sacrificed by cervical decapitation. The abdomen was opened and the liver specimen was quickly removed and opened gently using a scrapper, cleaned by rinsing with ice-cold isotonic saline to remove any blood cells, clots and scraps of food, then blotted between 2 filter papers and quickly stored in a deep freezer at $\left(-20{ }^{\circ} \mathrm{C}\right)$ for subsequent biochemical analysis. Briefly, liver tissues were divided into appropriate portions, homogenized with a glass homogenizer in 9 volume of ice-cold 0.05 $\mathrm{mM}$ potassium phosphate buffer $(\mathrm{pH} 7.4)$ to make $10 \%$ homogenates. The homogenates were centrifuged at 6000 r.p.m for 15 minutes at $4^{\circ} \mathrm{C}$ then the resultant supernatant were used for the determination of the following parameters: SOD, CAT, LMDA, DNA fragmentation percent, caspase-3 gene and nuclear factor kappa B P65.

For Histopathological examination: Liver specimen of rats was carefully examined by naked eyes for detection of any abnormalities. Small liver specimens were taken from different parts. The specimens were preserved in 10\% neutral buffered formalin solution and subjected for histopathological examination according to the technique described by Bancroft and Stevens, 1996.

\subsection{Biochemical analysis:}

Serum Alpha-Fetoprotein, Interleukin-6, tumor necrosis factor alpha and liver tissue SOD, CAT, L-MDA, DNA fragmentation percent, caspase-3 gene and nuclear factor kappa B P65 were analyzed according to the methods described by Rat ELISA Kit For Alpha-Fetoprotein (Designed by Cloud- 
Clone Corp., assembled by Uscn Life Science Inc. ISO9001:2008: ISO13485:2003, Catalog Number: MBS724171 according to the manufacturer's instruction); Chan and Perlstein, (1987); Beyaert and Fiers, (1998); Nishikimi et al., (1972); Aebi, (1984); Mesbah et al., (2004); Shi et al., (1997); mice Caspase- 3 (Casp-3) ELISA Kit (CUSABIO BIOTECH CO., LTD) Cat.No.CSB-E08857r) according to the manufacturer's instruction; Elisa Kit (Cat.No.MBS814487) according to the manufacturer's instruction, , respectively.

\subsection{Statistical analysis:}

The obtained data were analyzed and graphically represented using the statistical package for social science (SPSS, 13.0 software, 2009), for obtaining mean and standard deviation and error. The data were analyzed using one-way ANOVA to determine the statistical significance of differences among groups. Duncan's test was used for making a multiple comparison among the groups for testing the intergrouping homogeneity.

\section{RESULTS}

3.1. Protective and treatment effect of Omega-3 fatty acids on serum AFP, IL6 and TNF- $\alpha$ concentrations in $N$ nitrosodiethylamine -induced hepatocarcinogenesis in rats.

The obtained results in table (1) revealed that, a significant increase in serum AFP, IL- 6 and TNF- $\alpha$ levels were observed in liver cancer induced rats. Pretreatment and treatment with omega-3 in DEN-induced liver cancer in rats resulted in a significant decrease in serum AFP, IL- 6 and TNF- $\alpha$ levels when compared with liver cancer non treated group.

\subsection{Protective and treatment effect of} Omega-3 fatty acids on liver tissues SOD, CAT, L-MDA, DNA fragmentation, Caspase-3 and $N F-k B$ $P 65$ in N-nitrosodiethylamine -induced hepatocarcinogenesis in rats.
The obtained results presented in table (2) revealed that, a significant decrease in liver tissue super oxide dismutase (SOD) and catalase (CAT) activities were observed in liver cancer induced rats. On the other hand, a significant increase in liver tissue, LMalondialdhyde (L-MDA), DNA fragmentation percent, caspase-3 gene and nuclear factor kappa B P65 were observed in liver cancer induced rats when compared with control group. Pretreatment and treatment with omega-3 in DEN-induced liver cancer in rats resulted in nonsignificant increase in liver tissue super oxide dismutase (SOD) and a significant increase in catalase (CAT) activities. Meanwhile, the value of liver tissue LMalondialdhyde (L-MDA), DNA fragmentation percent, caspase-3 gene and nuclear factor kappa B P65 were significantly decreased when compared with liver cancer non treated group.

\subsection{Histopathological examination:}

The microscopical examination of liver of rats of diethylnitrosamine (DEN) injected group revealed severe congestion of the central vein, sinusoids and portal blood vessels. Moreover, severe thickening and hyalinization of wall of the portal blood vessels was seen (Fig 1A). Abnormal architecture of hepatocytes with extensive degree of degenerative changes in the form severe degree of fatty change in the cytoplasm of hepatocytes was observed. The hepatocytes showing the presence of clear vacuoles in their cytoplasm which squeezed the nucleus to over side giving it the shape of signet-ring was detected (Fig 1B). Moreover, the hepatocytes were suffering from necrotic changes in the form of pyknotic nuclei and more eosinophilic cytoplasm. Most of hepatocytes showing the criteria of neoplasia that represented in peleomorphism. The nucleus of most of hepatocytes showing hyper-chromacia and numerous mitotic figures with binucleated hepatocytes was observed (Fig 1C). Interestingly, pretreatment of rats with omega-3 (Daily dose $=270 \mathrm{mg} / \mathrm{kg}$ body 
weight) from the $2^{\text {nd }} \mathrm{wk}$ ) till the end of experiment (13 weeks), with injection of rats with DEN (200mg/Kg body weight) at experimental weeks 6, 8, (Group 3) revealed mild reduction in the neoplastic changes that was observed in DEN injected group (Group 2) as large number of abnormal hepatocytes were observed containing irregular minute clear vacuoles. In addition, individual coagulative necrosis of hepatocytes in which more eosinophilic cytoplasm of hepatocytes with vesicular nuclei was observed (Fig 1D). However, the anti-hepatocarcinogenic effect of Omega-3 in treated group (group 4) was demonstrated. Treatment of rats with omega -3 throughout oral gavages $(270 \mathrm{mg} / \mathrm{kg}$ b.w.) one week after DEN administration till the end of the experiment (13 weeks) (Group 4) improved the hepatocellular architecture with more regular and less altered hepatocytes when compared to Group 2. The liver showed mild congestion of the hepatic and portal blood vessels. Mild degenerative changes in the cytoplasm of hepatocytes in the form of hydropic degeneration were seen (Fig 1E). Furthermore, the liver cells were mostly mononucleated with regular sized nuclei. Moreover, criteria of neoplasia, as the nucleus of these hepatocytes become hyperchromatic and showing poliomorphism was observed only in one rat. Interestingly, the hepatic parenchyma of rats received Omega-3 only (group 5) showed normal architecture except only recent thrombosis of the portal blood vessels was seen only in few cases (Fig 1F).

Table (1): Protective and treatment effect of Omega-3 fatty acids on serum AFP, IL-6 and TNF$\alpha$ concentrations in N-nitrosodiethylamine -induced hepatocarcinogenesis in rats.

\begin{tabular}{llll}
\hline Parameters & $\begin{array}{l}\text { AFP } \\
\text { pg/ml }\end{array}$ & $\begin{array}{l}\text { IL-6 } \\
\text { pg/ml }\end{array}$ & $\begin{array}{l}\text { TNF- } \alpha \\
\text { g/dl }\end{array}$ \\
Exp. groups & & & \\
\hline Control & $35.67 \pm 10.82^{\mathrm{c}}$ & $51.82 \pm 6.07^{\mathrm{b}}$ & $14.06 \pm 2.06^{\mathrm{c}}$ \\
DEN(Positive control) & $119.21 \pm 12.59^{\mathrm{a}}$ & $225.78 \pm 38.18^{\mathrm{a}}$ & $66.64 \pm 8.27^{\mathrm{a}}$ \\
$\omega_{3+}$ DEN (Protected) & $75.18 \pm 9.67^{\mathrm{b}}$ & $70.13 \pm 14.53^{\mathrm{b}}$ & $34.07 \pm 5.03^{\mathrm{b}}$ \\
DEN $+\omega_{3}$ (Treated) & $57.08 \pm 5.07^{\mathrm{ab}}$ & $90.43 \pm 11.14^{\mathrm{b}}$ & $32.19 \pm 3.45^{\mathrm{b}}$ \\
Omega-3 & $35.51 \pm 4.06^{\mathrm{c}}$ & $69.50 \pm 9.50^{\mathrm{b}}$ & $8.54 \pm 0.79^{\mathrm{c}}$ \\
\hline
\end{tabular}

Data are presented as (Mean \pm S.E). S.E $=$ Standard error. Mean values with different superscript letters in the same column are significantly different at $(P \leq 0.05)$.

Table (2): Protective and treatment effect of Omega-3 fatty acids on liver tissues SOD, CAT, L-MDA, DNA fragmentation, Caspase-3 and NF-kB P65 in N-nitrosodiethylamine -induced hepatocarcinogenesis in rats.

\begin{tabular}{lllllll}
\hline Parameters & $\begin{array}{l}\text { SOD } \\
\text { U/g tissue }\end{array}$ & $\begin{array}{l}\text { CAT } \\
\text { mmol/g. tissue }\end{array}$ & $\begin{array}{l}\text { L-MDA } \\
\text { mmol/g. tissue }\end{array}$ & $\begin{array}{l}\text { DNA } \\
\text { Exagmentation } \\
\text { cell/g. tissue }\end{array}$ & $\begin{array}{l}\text { Caspase-3 } \\
\text { ng/g.tissue }\end{array}$ & $\begin{array}{l}\text { NF-kB P65 } \\
\text { ng/g.tissue }\end{array}$ \\
\hline Control & $44.78 \pm 4.74^{\mathrm{a}}$ & $65.87 \pm 3.21^{\mathrm{a}}$ & $26.72 \pm 7.12^{\mathrm{c}}$ & $100.54 \pm 44.25^{\mathrm{b}}$ & $0.62 \pm 0.09^{\mathrm{c}}$ & $5.14 \pm 0.59^{\mathrm{c}}$ \\
DEN & $12.62 \pm 1.68^{\mathrm{b}}$ & $31.45 \pm 1.64^{\mathrm{c}}$ & $184.38 \pm 21.55^{\mathrm{a}}$ & $3464.38 \pm 1411.46^{\mathrm{a}}$ & $3.01 \pm 0.22^{\mathrm{a}}$ & $12.63 \pm 0.68^{\mathrm{a}}$ \\
$\omega_{3+} \mathrm{DEN}$ & $17.68 \pm 2.10^{\mathrm{b}}$ & $45.25 \pm 3.24^{\mathrm{b}}$ & $100.94 \pm 11.64^{\mathrm{b}}$ & $663.72 \pm 81.44^{\mathrm{b}}$ & $2.30 \pm 0.19^{\mathrm{b}}$ & $8.26 \pm 0.74^{\mathrm{b}}$ \\
DEN $+\omega_{3}$ & $23.16 \pm 3.97^{\mathrm{b}}$ & $51.75 \pm 4.65^{\mathrm{b}}$ & $70.65 \pm 14.73^{\mathrm{b}}$ & $747.50 \pm 67.00^{\mathrm{b}}$ & $1.84 \pm 0.12^{\mathrm{b}}$ & $6.67 \pm 0.75^{\mathrm{bc}}$ \\
Omega-3 & $39.14 \pm 3.39^{\mathrm{a}}$ & $66.58 \pm 5.10 \mathrm{a}$ & $68.95 \pm 3.71^{\mathrm{b}}$ & $102.36 \pm 32.11^{\mathrm{b}}$ & $0.70 \pm 0.13^{\mathrm{c}}$ & $5.34 \pm 1.15^{\mathrm{c}}$ \\
\hline
\end{tabular}


Figure 1:

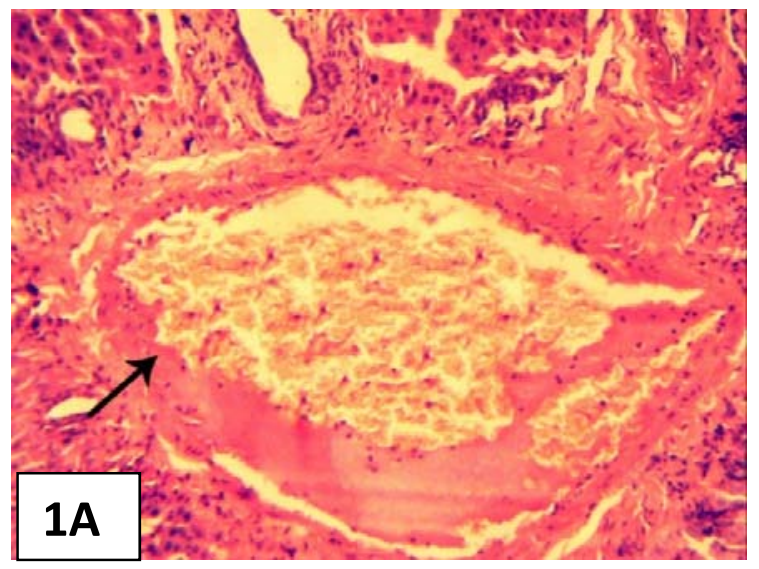

Liver of rats received 3doses DEN 200mg $/ \mathrm{kg}$ body weight inter-peritoneally at 15 days' intervals at experimental weeks 2, 4 and 6, showing thickening and hyalinization of the portal blood vessels (arrow). (H \& E, x200).

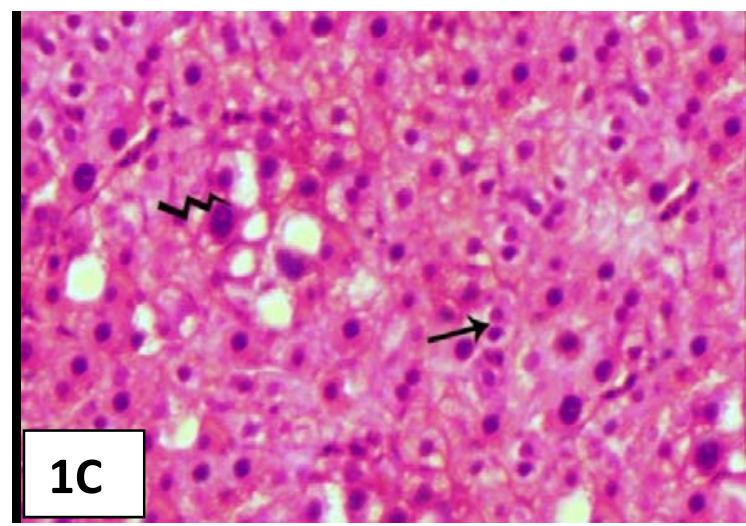

Liver of rats received 3 doses DEN $200 \mathrm{mg} / \mathrm{kg}$ body weight inter-peritoneally at 15 days' intervals at experimental weeks 2,4 and 6 showing criteria of malignancy hyperchromasia and poleomrphism (zigzag arrow). Notice also, bi-nucleated hepatocytes (arrow). (H\&E, x400).

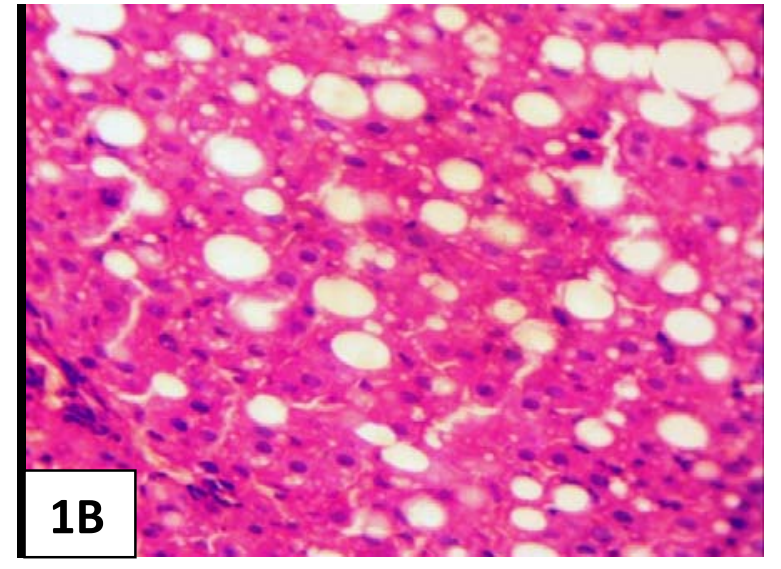

Liver of rats received 3doses DEN $200 \mathrm{mg} / \mathrm{kg}$ body weight inter-peritoneally at 15 days intervals at experimental weeks 2, 4 and 6 showing clear vacuoles in the cytoplasm of hepatocytes with squeezing the nucleus to over side giving signet- ring shape. (H \& E, x200).

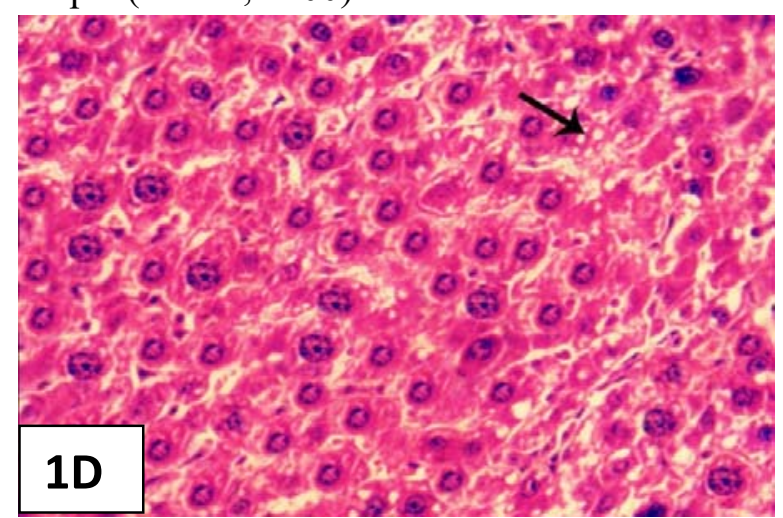

Liver of rats were pretreated with omega-

3 (Daily dose $=270 \mathrm{mg} / \mathrm{kg}$ body weight) (beginning from the $2^{\text {nd }} \mathrm{wk}$ ) till the end of experiment (13 weeks), and rats were injected with DEN (200 mg/Kg body weight) at experimental weeks $6,8,10$, showing minute clear vacuoles in the cytoplasm of hepatocytes (arrow) with vesicular nuclei and individual necrosis of hepatocytes. (H\&E, x200) 


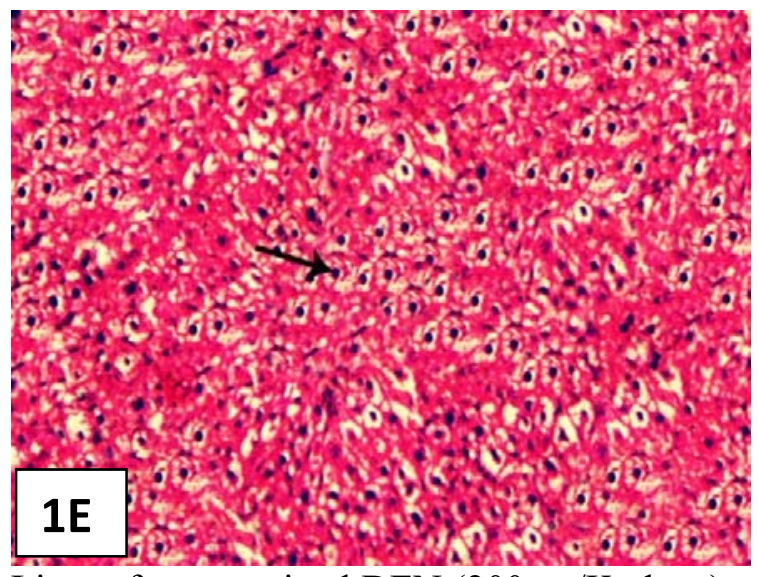

Liver of rats received DEN (200mg/Kg b.w.) at experimental weeks 2,4and 6 and subsequently treated with omega -3 throughout oral gavages $(270 \mathrm{mg} / \mathrm{kg} \mathrm{b.w.)}$ one week after DEN administration till the end of the experiment (13 weeks), showing hydropic degeneration in the cytoplasm of hepatocytes with pyknotic nuclei (arrow). (H\&E, x100)

\section{DISCUSSION}

$N$-Nitrosodiethylamine (DEN) causes a wide range of tumors in all animal species and such compounds are hazardous to human health. The formation of reactive oxygen species (ROS) is apparent during the metabolic biotransformation of DEN resulting in oxidative stress. Oxidative stress leads to carcinogenesis by several mechanisms including DNA, lipid and protein damage, change in intracellular signaling pathways and even changes in gene expression (Balamurugan and Karthikeyan, 2012). In the present study, the obtained data revealed a significant increase in serum AFP. AFP serum levels are often elevated in $\mathrm{HCC}$, but this is not always the case. AFP levels may be elevated initially in the early stages of HCC and then drop or even normalize before rising again as disease progression occurs. Moreover, AFP elevation has also been recognized in the presence of acute and chronic viral hepatitis as well as in patients with cirrhosis caused by hepatitis C. Given the multiple indications that present with elevated AFP levels, it is necessary to

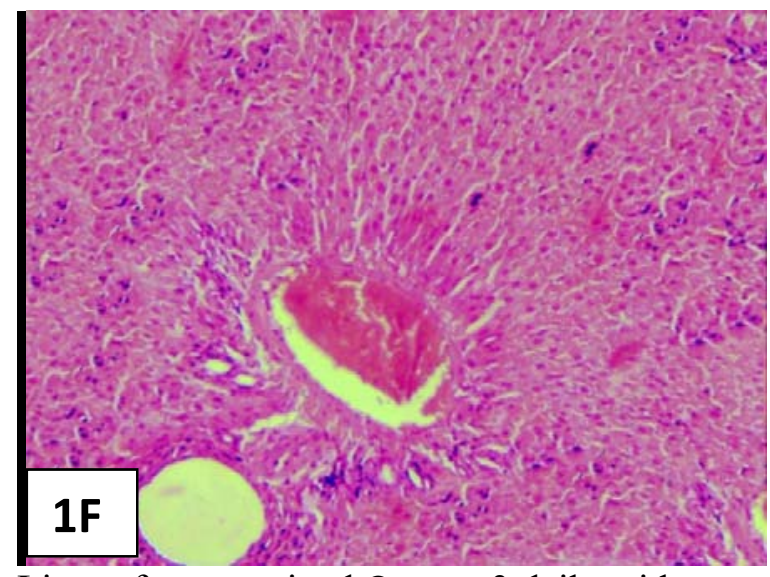

Liver of rats received Omega-3 daily with a dose of $270 \mathrm{mg} / \mathrm{kg}$ body weight (starting from $2^{\text {nd }}$ wk of experiment) till the end of experiment (13 weeks), showing recent thrombosis of portal blood vessels ( $\mathrm{H} \& \mathrm{E}$, $\mathrm{x} 100)$.

evaluate the significance of serum concentrations. Several studies that used DEN for HCC induction in albino rats give similar serum AFP elevation such as Metwally et al., 2011; Rajasekaran et al., 2011 and Chen et al., 2012. In the current study, a significant increase in serum TNF$\alpha$ and IL-6 levels was determined. High levels of pro-inflammatory TNF- $\alpha$ have been associated with carcinogenesis. TNF$\alpha$ expression was elevated in HCC patients, especially those with recurrence. An increased level of TNF- $\alpha$ was also shown to correlate with hepatic inflammation, necrosis, and hepatic failure (Budhu and Wang, 2006). These findings are clarified the obtained pathological changes in the liver of rats treated with DEN. In patients with chronic liver inflammation, serum IL6 levels are elevated including alcoholic hepatitis, HCV, HBV infections, and steatohepatitis. Many studies indicated a big role for IL-6 in the process of liver damage and carcinogenesis (Othman et al., 2012). Furthermore, a significant decrease in tissue SOD and CAT activities was detected in the current work in group 2. It has been proposed that oxidative stress 
plays an important role in the progress and development of various cancer types, including liver cancer. Free oxygen radicals are primarily removed by various enzymatic antioxidants, such as SOD, CAT, GPX and GST and by various nonenzymatic antioxidants, such as glutathione (GSH), $\alpha$-tocopherol and vitamin C (Arslan et al., 2014). A loss in catalase activity during cancer development is associated with tumor formation and metastasis. ROS may downregulate catalase through the methylation of promoter during the development of HCC (Min et al., 2010). The obtained data presented in table (2) revealed that, a significant increase in tissue MDA activity. Many studies reported that serum MDA levels of primary and metastatic liver cancer patients are significantly higher than the normal group. The high lipid peroxidation in liver cancer may be due to excessive ROS production. MDA may react with the amino acid residue of proteins, resulting in their oxidative modification and causing protein breakdown in the process. Moreover, it may encourage cellular use of glutathione and increase oxidative stress by deactivating selenium dependent glutathione peroxidases (Arslan et al., 2014). The obtained data presented in table (2) revealed that, a significant increase in tissue DNA fragmentation, caspase-3 gene and NF- $\kappa \mathrm{B}$. DNA fragmentation and caspase- 3 gene are markers of cell apoptosis. In particular, the balance between cell proliferation and cell death may play an important role in hepatocarcinogenesis. NF- $\kappa \mathrm{B}$ is found in almost all animal cell types and is involved in cellular responses to stimuli such as cytokines, stress, free radicals, oxidized LDL, ultraviolet irradiation, and bacterial or viral antigens. Incorrect regulation of NF$\kappa \mathrm{B}$ has been linked to cancer, inflammatory and autoimmune diseases, septic shock, viral infection, and improper immune development. NF- $\mathrm{BB}$ has also been implicated in processes of synaptic plasticity and memory (Brasier, 2006; Gilmore, 2006 and Perkins, 2007). It is known that NF- $\kappa \mathrm{B}$ plays an important role during liver neoplastic development via transcriptional regulation of pro-survival genes, which then affect death-inducing signals elicited by the host immune response (Factor et al., 2001). However, the histopathological examination of liver obtained from rats injected with DEN revealed criteria of neoplasia in hepatic parenchyma. These results could be attributed to the ability of DEN treatment in rat to causes enzymatic and non-enzymatic antioxidant defence depletion in hepatic tissue resulting in neoplastic changes in rat with a substantial increase of mitochondrial ROS. In this study, the protective effect of omega-3 against DEN-induced hepatocarcinogenesis in albino rats was proven. Omega-3 significantly lowered the serum levels of AFP, IL- 6 and TNF- $\alpha$ concentration and activity of liver MDA, caspase-3 gene, NF-kB P65 and DNA fragmentation percent. In contrast it increased the activities of liver SOD and CAT. Omega-3, important poly unsaturated fatty acids involved in human nutrition, are $\alpha$-linolenic acid (ALA), eicosapentaenoic acid (EPA), docosapentaenoic acid (DPA). Since the mid-1980s, a renewed interest in omega-3 fatty acids revealed that they have an important role in the cause and management of several diseases such as cancer, psychiatric, cardiovascular disorders, inflammatory bowel disease and cystic fibrosis (Stephenson et al., 2013).

Omega-3 fatty acids have been shown to have multiple antitumor actions that affect all of the malignant growth six essential alterations that described previously. This is a result of many pathways including the regulation of the immune system by acting as precursors for eicosanoids-potent immunoregulatory metabolites. The $n-3$ poly unsaturated fatty acids are metabolized by cyclooxygenase (COX) or lipoxygenase (LOX) enzymes into immunoregulatory metabolites prostaglandins (PGs), thromboxanes (TXs), and leukotrienes (LTs). These compounds are well documented that inflammation plays an 
important role in the development of numerous human malignancies. They have independent effects on various cytokines involved in tumourigenesis (Coussens and Werb, 2002; Clevers, 2004; Karin, 2006 and Stephenson et al., 2013). In the present work, histopathological analysis confirmed the pathological improvement in the hepatic tissue of rats either pre-treated or treated groups (group 3 and 4). A recent study was carried out to investigate the hepatoprotective effect of fish oil, diet that rich in $\omega-3$ PUFAs, against DEN intoxication in rats. However, a significantly increment in the activities of superoxide dismutase, catalase, glutathione peroxidase and glutathione reduced were observed in blood of hepatotoxicity rats treated with fish oil. The treated groups showed a significant decrement in thiobarbituric acid reactive substances (MDA) in serum. Since the study of induction of the redox enzymes is considered to be a reliable marker for evaluating the antiperoxidative efficacy of the fish oil. Treatment with fish oil reduces the histopathological liver abnormalities associated with hepatotoxicity. Moreover, to the anti-hepatotoxicity effect and possess antioxidant potential that may be used for therapeutic purposes suggested. Thus this study showed that fish oil was able to prevent or reduce the severity of diethylnitrosamine -induced liver injury (Hassanen and Ahmed, 2015).

\section{CONCLUSION}

In conclusion, the present study demonstrated that omega-3 administration provided an effective protection and treatment against hepatic carcinogenesis and oxidative damage in liver tissue induced by DEN in rats, since omega-3 was able to ameliorate serum biochemical parameters, enzymatic and non-enzymatic antioxidant defense system in liver tissue. The results indicate that omega-3 exerts chemopreventive effect by restoring the activities of hepatic marker enzymes and reversing the oxidant-antioxidant imbalance during NDEA-induced hepatocarcinogenesis. Results of the present investigation provide evidence that attenuation of oxidative stress and suppression of inflammatory response mediated by NF-kB could be implicated, at least in part, in the chemopreventive effects of this dietary fatty acids against chemically induced hepatic tumorigenesis in rats. The outcome of this study may benefit the development of omega- 3 fatty acids in the prevention and intervention of human HCC. We recommended that, administration of diet rich in the antioxidant omega-3 is very important for treatment and protection of different body tissue, especially liver tissue, against oxidative stress or even inflammation or cancer.

\section{REFERENCES}

Aebi, H. 1984. Catalase in vitro assay methods. Methods in Enzimology; 105:121-126.

Alwayn, I.P., Gura, K., Nosé, V., Zausche, B., Javid, P., Garza, J., Verbesey, J., Voss, S., Ollero, M., Andersson, C., Bistrian, B., Folkman, J., Puder, M. 2005. Omega-3 fatty acid supplementation prevents hepatic steatosis in a murine model of nonalcoholic fatty liver disease. Pediatr Res; 57: 445-452.

Araya, J., Rodrigo, R., Videla, L.A., Thielemann, L., Orellana, M., Pettinelli, P., Poniachik, J. 2004. Increase in long-chain polyunsaturated fatty acid $n-6 / n-3$ ratio in relation to hepatic steatosis in non-alcoholic fatty liver disease patients. Clin Sci (Lond); 106: 635643.

Arslan, A., Demir, H., Ozbay, M.F., Arslan, H. 2014. Evaluation of Lipid Peroxidation and Some Antioxidant Activities in Patients with Primary and Metastatic Liver Cancer. Journal of Cancer Therapy; 5: 192-197. 
Arvindakshan, M., Ghate, M., Ranjekar, P.K., Evans, D.R., Mahadik, S.P. 2003. Supplementation with a combination of omega-3 fatty acids and antioxidants (vitamins $\mathrm{E}$ and $\mathrm{C}$ ) improves the outcome of schizophrenia. Schizophr Res; 62: 195-204.

Balamurugan, K., Karthikeyan, J. 2012. Evaluation of Luteolin in the Prevention of N-nitrosodiethylamineinduced Hepatocellular Carcinoma Using Animal Model System. Indian J Clin Biochem.; 27: 157-163.

Bancroft, J.D., Stevens, A. 1996. Theory and Practice of Histological Techniques. 4nd ed. Edinburgh: Churchill Livingstone. 766 p.

Beyaert, R., Fiers, W. 1998. Tumor Necrosis Factor and Lymphotoxin. In Cytokines, A.R.M.-S. a. R. Thorpe, eds. Academic Press, San Diego; 335360.

Brasier, A.R. 2006. The NF-kappaB regulatory network. Cardiovasc Toxicol.; 6: 111-30.

Budhu, A., Wang, X.W. 2006. The role of cytokines in hepatocellular carcinoma. J Leukoc Biol.; 80:11971213.

Chan, D.W., Perlstein, N.T. 1987. Immunology: A practical Guide Eds, Academic: Press: New York, p71.

Chen, G., Dai, Z.K., Liang, R.G., Xiao, S.J., He, S.Q., Zhao, H.L., Xu, Q. 2012. Characterization of diethylnitrosamine-induced liver carcinogenesis in Syrian golden hamsters. Exp Ther Med.; 3: 285-292.

Clevers, H. 2004. At the crossroads of inflammation and cancer. Cell; 118: 671-674.

Coussens, L.M., Werb, Z. 2002. Inflammation and cancer. Nature; 420: 860-867.

De Vizia, B., Raia, V., Spano, C., Pavlidis, C., Coruzzo, A., Alessio, M. 2003. Effect of an 8-month treatment with omega-3 fatty acids (eicosapentaenoic and docosahexaenoic) in patients with cystic fibrosis. JPEN J Parenter Enteral Nutr; 27: 52-57.

Factor, V., Oliver, A.L., Panta, G.R., Thorgeirsson, S.S., Sonenshein, G.E., Arsra, M. 2001. Roles of Akt/PKB and IKK complex in constitutive induction of $\mathrm{NF} \kappa \mathrm{B}$ in hepatocellular carcinomas of transforming growth factor $\alpha / c-m y c$ transgenic mice, Hepatology 34: 32 41.

Forner, A., Llovet, J.M., Bruix, J. 2012. Hepatocellular carcinoma. Lancet; 379: 1245-1255.

Freeman, M.P. 2000. Omega-3 fatty acids in psychiatry: a review. Ann Clin Psychiatry; 12: 159-165.

Gilmore, T.D. 2006. Introduction to NFkappaB: players, pathways, perspectives. Oncogene.; 25: 66806684.

Hassanen, N.H.M., Ahmed, M.H.M. 2015. Protective Effect of Fish Oil and Virgin Olive Oil on Diethylnitrosamine Toxicity in Rats. International Journal of Nutrition and Food Sciences; 4: 388-396.

Karin, M. 2006. Nuclear factor-kappaB in cancer development and progression. Nature; 441: 431-436.

Khan, M.S., Devaraj, H., Devaraj, N. 2011. Chrysin abrogates early hepatocarcinogenesis and induces apoptosis in N-nitrosodiethylamineinduced preneoplastic nodules in rats. Toxicol Appl Pharmacol,; 251: 85-94.

Leaf, A., Kang, J.X., Xiao, Y.F., Billman, G.E. 2003. Clinical prevention of sudden cardiac death by n-3 polyunsaturated fatty acids and mechanism of prevention of arrhythmias by n-3 fish oils. Circulation; 107: 2646-2652.

Mata Lopez, P., Ortega, R.M. 2003. Omega-3 fatty acids in the prevention and control of cardiovascular disease. Eur J Clin Nutr; 57: S22-S25.

Mesbah, L., Soraya, B., Narimane, S., and Jean, P.F. 2004. protective effect of flavonides against the toxicity of 
vinblastine cyclophosphamide and paracetamol by inhibition of lipid peroxydation and increase of liver glutathione. Haematol.; 7: 59-67.

Metwally, N.S., Kholeif, T.E., Ghanem, K.Z., Farrag, A.R., Ammar, N.M., Abdel-Hamid, A.H. 2011. The protective effects of fish oil and artichoke on hepatocellular carcinoma in rats. Eur Rev Med Pharmacol Sci.; 15: 1429-1444.

Min, J.Y., Lim, S.O., Jung G. 2010. Downregulation of catalase by reactive oxygen species via hypermethylation of $\mathrm{CpG}$ island II on the catalase promoter. FEBS Lett.; 584: 2427-2432.

$\mathrm{Mu}, \mathrm{X}$., Español-Suñer, R., Mederacke, I., Affò, S., Manco, R., Sempoux, C., Lemaigre, F.P., Adili, A., Yuan, D., Weber, A., Unger, K., Heikenwälder, M., Leclercq, I.A., Schwabe, R.F. 2015. Hepatocellular carcinoma originates from hepatocytes and not from the progenitor/biliary compartment. J Clin Invest; 125: 3891-3903.

Nishikimi, M., Appaji, N., Yagi, K. 1972. The occurrence of superoxide anion in the reaction of reduced phenazine methosulfate and molecular oxygen. Biochem Biophys Res Commun; 46: 849-854.

Othman, M.S., Aref, A.M., Mohamed, A.A., Ibrahim, W.A. 2012. Serum Levels of Interleukin-6 and Interleukin-10 as Biomarkers for Hepatocellular Carcinoma in Egyptian Patients. ISRN Hepatology; 2013: 9.

Paget, G. E., Barnes, J. M. 1964. Toxicity test. In: Laurence, D. R. Bacharach, A. L.; editors. Evaluation of drug activities: Pharmacometric. London and New York: Academic press. 134166

Park, Y., Harris, W.S. 2003. Omega-3 fatty acid supplementation accelerates chylomicron triglyceride clearance. $\mathrm{J}$ Lipid Res; 44: 455-463.
Perkins, N.D. 2007. Integrating cellsignalling pathways with NF-kappaB and IKK function. Nat Rev Mol Cell Biol.; 8: 49-62.

Rajasekaran, D., Elavarasan, J., Sivalingam, M., Ganapathy, E., Kumar, A., Kalpana, K., and Sakthisekaran, D. 2011. Resveratrol interferes with Nnitrosodiethylamine-induced hepatocellular carcinoma at early and advanced stages in male Wistar rats. Mol Med Rep.; 4: 1211-1217.

Saini, N., Bhagat, A., Sharma, S., Duseja, A., Chawla, Y. 2006. Evaluation of clinical and biochemical parameters in hepatocellular carcinoma: experience from an Indian center. Clin. Chim. Acta; 371: 183-186.

Shi, L., Mai, S., Israels, S., Browne, K., Trapani, J.A., Greenberg, A.H. 1997. Granzyme B (GraB) autonomously crosses the cell membrane and perforin initiates apoptosis and GraB nuclear localization. J. Exp. Med.; 185: 855-866.

Simopoulos, A.P. 2002. Omega-3 fatty acids in inflammation and autoimmune diseases. J Am Coll Nutr; 21: 495-505.

Singh, B.N., Singh, B.R., Sarma, B.K. and Singh, H.B. 2009. Potential chemoprevetio of Nnitrosodiethylamine-induced hepatocarcinogenesis by polyphenolics from Acacia nilotica bark. Chem Biol Interact. 181: 20-28.

Stephenson, J.A., Al-Taan, O., Arshad, A., Morgan, B., Metcalfe, M.S., Dennison, A.R. 2013. The multifaceted effects of omega-3 polyunsaturated Fatty acids on the hallmarks of cancer. J Lipids; 261247.

Su, K.P., Huang, S.Y., Chiu C.C., Shen WW. 2003. Omega-3 fatty acids in major depressive disorder. A preliminary double-blind, placebo-controlled trial. Eur Neuropsychopharmacol; 13: 267271. 